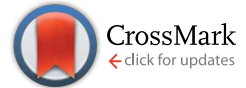

Cite this: Chem. Sci., 2015, 6, 4855

\title{
Unravelling the $\mathrm{pH}$-dependence of a molecular photocatalytic system for hydrogen production $\dagger$
}

\author{
Anna Reynal, ${ }^{\text {,ab }}$ Ernest Pastor, ${ }^{a}$ Manuela A. Gross, ${ }^{c}$ Shababa Selim, ${ }^{a}$ Erwin Reisner ${ }^{\star c}$ \\ and James R. Durrant*a
}

\begin{abstract}
Photocatalytic systems for the reduction of aqueous protons are strongly $\mathrm{pH}$-dependent, but the origin of this dependency is still not fully understood. We have studied the effect of different degrees of acidity on the electron transfer dynamics and catalysis taking place in a homogeneous photocatalytic system composed of a phosphonated ruthenium tris(bipyridine) dye (RuP) and a nickel bis(diphosphine) electrocatalyst (NiP) in an aqueous ascorbic acid solution. Our approach is based on transient absorption spectroscopy studies of the efficiency of photo-reduction of RuP and NiP correlated with $\mathrm{pH}$-dependent photocatalytic $\mathrm{H}_{2}$ production and the degree of catalyst protonation. The influence of these factors results in an observed optimum photoactivity at $\mathrm{pH} 4.5$ for the RuP-NiP system. The electron transfer from photo-reduced RuP to NiP is efficient and independent of the $\mathrm{pH}$ value of the medium. At $\mathrm{pH}<4.5$, the efficiency of the system is limited by the yield of RuP photo-reduction by the sacrificial electron donor, ascorbic acid. At $\mathrm{pH}>4.5$, the efficiency of the system is limited by the poor protonation of NiP, which inhibits its ability to reduce protons to hydrogen. We have therefore developed a rational strategy utilising transient absorption spectroscopy combined with bulk $\mathrm{pH}$ titration, electrocatalytic and photocatalytic experiments to disentangle the complex pH-dependent activity of the homogenous RuP-NiP photocatalytic system, which can be widely applied to other photocatalytic systems.
\end{abstract}

Received 14th April 2015

Accepted 27th May 2015

DOI: $10.1039 / \mathrm{c} 5 \mathrm{sc} 01349 f$

www.rsc.org/chemicalscience

\section{Introduction}

The photochemical production of $\mathrm{H}_{2}$ from water is a rapidly expanding research field that aims to store solar energy in a chemical fuel. ${ }^{1}$ From the viewpoint of sustainability and economic viability, this proton reduction reaction should be carried out in aqueous conditions and use stable and Earth abundant materials. ${ }^{2}$ Current investigations for solar $\mathrm{H}_{2}$ synthesis include molecular dyes and electrocatalysts based on nickel, iron and cobalt, either in solution or immobilised onto the surface of a semiconductor. ${ }^{3-12}$ These photocatalytic systems typically require the use of sacrificial chemical reductants to provide the electrons to regenerate the oxidised dye following proton reduction.

The efficiency of $\mathrm{H}_{2}$ evolving photo- and electrocatalytic systems is typically strongly $\mathrm{pH}$ dependent. ${ }^{13-16}$ Understanding the origins of this $\mathrm{pH}$ dependence is critical to guide further

${ }^{a}$ Department of Chemistry, Imperial College London, Exhibition Road, London SW7 2AZ, UK. E-mail: j.durrant@imperial.ac.uk

${ }^{b}$ School of Chemistry, Newcastle University, Newcastle Upon Tyne, NE1 7RU, UK. E-mail: anna.reynal@ncl.ac.uk

${ }^{c}$ Christian Doppler Laboratory for Sustainable SynGas Chemistry, Department of Chemistry, University of Cambridge, Lensfield Road, Cambridge CB2 1EW, UK. E-mail: reisner@ch.cam.ac.uk

$\dagger$ Electronic supplementary information (ESI) available. See DOI: $10.1039 / \mathrm{c} 5 \mathrm{sc} 01349 \mathrm{f}$ system development and optimisation. In particular, it is essential to determine whether such $\mathrm{pH}$ dependencies derive from the availability of protons to the molecular catalyst, from the function of the molecular light-harvesting unit or from the sacrificial electron donor.

We have recently reported a homogeneous photocatalytic system based on a molecular ruthenium photosensitiser (RuP) and a nickel catalyst (NiP) capable of producing $\mathrm{H}_{2}$ in pure water with a quantum efficiency near $10 \%$ in the presence of ascorbic acid (AA) as a sacrificial electron donor (Fig. 1). ${ }^{17}$ In this system, the electron transfer from the photoreduced dye $\left(\mathbf{R u P}^{-}\right)$ to NiP takes place following reductive quenching of the photoexcited dye in the presence of the sacrificial agent, AA (Scheme 1). Under visible light irradiation, optimum performance of this photocatalytic system was observed at $\mathrm{pH}$ 4.5. In contrast, when used as an electrocatalyst, the proton reduction efficiency of the NiP catalyst was observed to increase towards more acidic $\mathrm{pH} .{ }^{17}$ This $\mathrm{pH}$ dependence is typical of this type of nickel-based molecular electrocatalysts, and has been attributed to the presence of pendant amines with low $\mathrm{p} K_{\mathrm{a}}$, which are thought to act as a proton relay between the solvent and the metal centre. $^{13,18-20}$

Studies reporting the dependence of $\mathrm{H}_{2}$ evolution on the acidity of the aqueous media for molecular photocatalytic systems have typically focused on the overall system efficiency as a function of $\mathrm{pH} \cdot{ }^{13-15,21}$ Reaction mechanisms, where studied, 


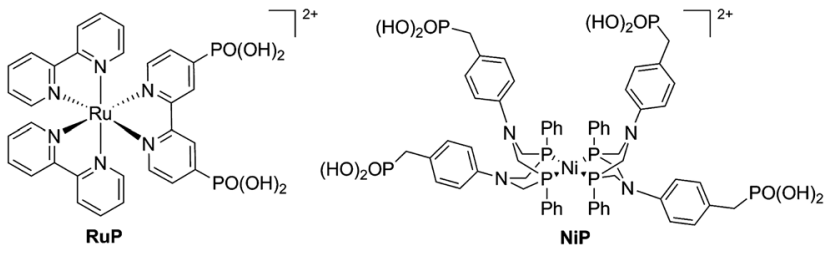

Fig. 1 Molecular structures of the phosphonated ruthenium dye (RuP) and the nickel $\mathrm{H}_{2}$ evolution catalyst (NiP). The bromide counter ions have been omitted for clarity.

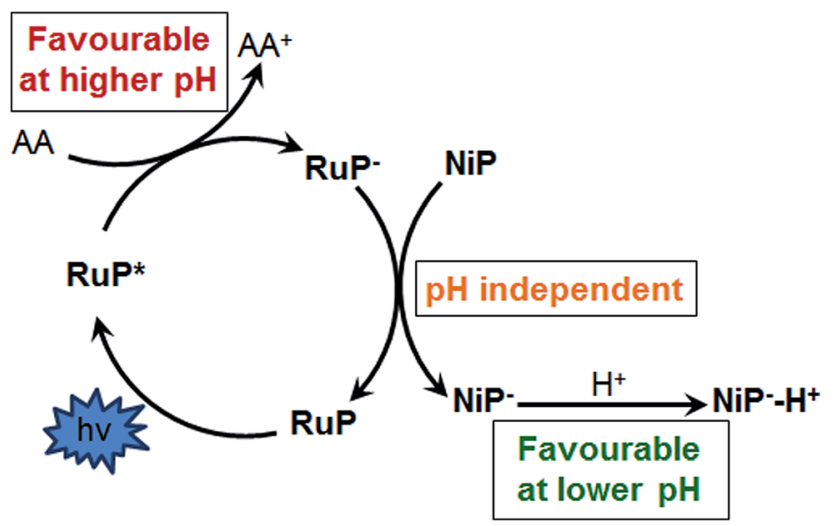

Scheme 1 Schematic representation of the reductive electron transfer mechanism between RuP and NiP in the presence of ascorbic acid as sacrificial electron donor.

have been addressed through theoretical calculations and experimental techniques such as nuclear magnetic resonance spectroscopy, electrochemistry and steady state spectroscopy; ${ }^{7,22-24}$ and to a lesser extent, time-resolved absorption spectroscopy. ${ }^{15,24-34}$ Herein, we report on the influence of the solution acidity on the formation of the photo-reduced RuP $^{-}$ species, the electron transfer kinetics between the optically active $\mathbf{R u P}^{-}$and $\mathbf{N i P}$, as well as the $\mathrm{pH}$ dependence of $\mathrm{H}_{2}$ evolution observed in electrochemical and bulk photocatalytic experiments. We have employed transient absorption spectroscopy, combined with electrochemical experiments, to determine the working principles of this photocatalytic system. The correlation of these results allowed us to determine the $\mathrm{pH}-$ dependent rate-limiting steps in the photocatalytic system and give a rational explanation for the observed optimal activity at $\mathrm{pH} 4.5$, as well as to provide a timescale for the electron transfer (ET) reactions between the sacrificial electron donor, the dye and the catalyst. Experimental details are described in the ESI. $\dagger$

\section{Results and discussion}

At $\mathrm{pH} 4.5$, photoexcitation of RuP in the presence of AA leads to the efficient formation of $\mathbf{R u P}^{-}$within $t_{50 \%} \sim 250 \mathrm{~ns}$ through a reductive quenching mechanism, with a quantum yield estimated from transient emission studies of approximately $70 \% .{ }^{17}$ The reduced photosensitiser $\mathbf{R u P}^{-}$shows a transient absorption peak at $\lambda=500 \mathrm{~nm}$ with a lifetime $\left(t_{50 \%}\right.$, calculations detailed in
Fig. S1 $\dagger$ ) of $500-700 \mu$ s (Fig. 2). ${ }^{35}$ The yield of RuP $^{-}$produced at different $\mathrm{pH}$ values can be determined from the initial amplitude (at $\sim 10 \mu \mathrm{s}$ ) of this $\mathbf{R u P}^{-}$transient absorption signal at $\lambda=$ $500 \mathrm{~nm}$. It is apparent (Fig. 2, inset) that this assay of the yield of $\mathbf{R u P}^{-}$increases with increasing $\mathrm{pH}$, reaching a maximum at $\mathrm{pH}$ $=5$. This behaviour can be explained by the different reactivity of two protonation states of ascorbic acid present in the $\mathrm{pH}$ range studied herein. At low $\mathrm{pH}$, ascorbic acid exists primarily in its undissociated form $\mathrm{H}_{2} \mathrm{~A}\left(\mathrm{p} K_{\mathrm{a}}=4.17\right)$, whereas the monoprotic ascorbate anion $\left(\mathrm{HA}^{-}\right)$predominates at higher $\mathrm{pH}$ values $\left(\mathrm{p} K_{\mathrm{a}}=11.57\right)$. The ascorbate anion is a stronger reducing agent than its protonated form, and thus the reductive quenching of the excited dye, $\mathbf{R u P}^{*}$, is favoured at $\mathrm{pH}>4$, where $\mathrm{HA}^{-}$is the dominating species. ${ }^{36-38}$

After the formation of $\mathbf{R u P}^{-}$, electrons should be transferred from the reduced dye to the catalyst. In the presence of NiP, the positive transient absorption signal corresponding to $\mathbf{R u P}^{-}$ absorption at $\lambda=500 \mathrm{~nm}$ is rapidly quenched (within $50-100 \mu \mathrm{s}$ on the range of $\mathrm{pH}$ values studied herein), leading to the appearance of a negative signal at longer timescales (500 $\mu$ s to $1 \mathrm{~s}$; Fig. 3 and $\mathbf{S} 2 \dagger$ ). This negative signal is assigned to electron transfer from $\mathbf{R u P}^{-}$to NiP, resulting in bleaching of ground state absorption of NiP. ${ }^{17}$ This bleach is not observed in the absence of either RuP or NiP (see for example Fig. 2 and S3†), suggesting that it is due to intermolecular electron transfer (ET) between $\mathbf{R u P}^{-}$and NiP (rather than the direct photoexcitation of NiP). The fast electron transfer kinetics between $\mathbf{R u P}^{-}$and $\mathbf{N i P}$ at all studied $\mathrm{pH}$ values suggests that this process is not limiting the catalytic activity of NiP (Fig. S2 $\dagger$ ). However, the long-lived transient absorption bleach signal corresponding to reduced NiP indicates that the subsequent protonation step is more likely to be the rate limiting reaction. We can also estimate the yield of NiP reduced by $\mathbf{R u P}^{-}$from the amplitude of the bleach (Fig. 3 inset). Thus, a greater negative signal indicates the reduction of more NiP due to ET from $\mathbf{R u P}^{-}$. It is apparent

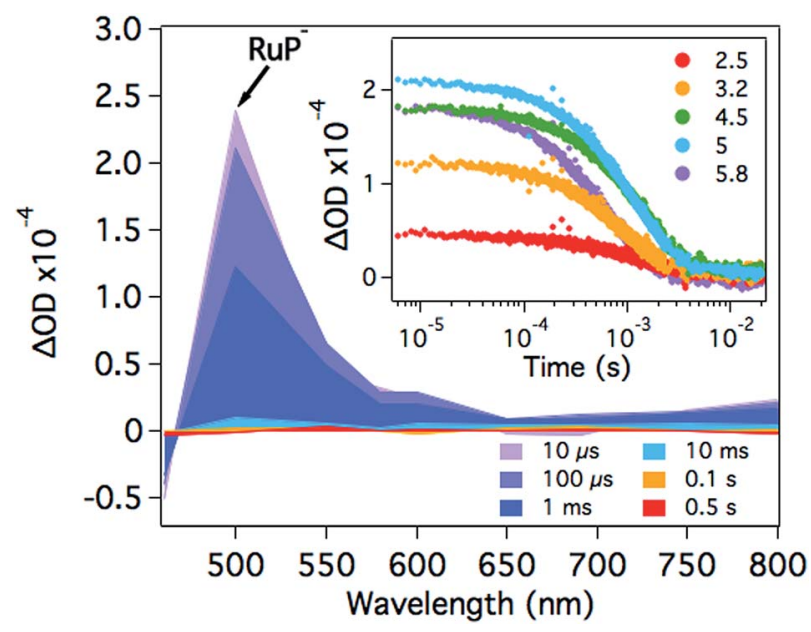

Fig. 2 Transient absorption spectra of RuP $(4 \mu \mathrm{M})$ in the presence of AA $(0.1 \mathrm{M})$ at $\mathrm{pH} 4.5$ as a function of time delay. The inset shows the corresponding kinetics probed at $\lambda=500 \mathrm{~nm}$ in the $\mathrm{pH}$ range between 2.5 and 5.8. The samples were excited at $\lambda=355 \mathrm{~nm}$. 
that the yield of reduced NiP increases as the $\mathrm{pH}$ is increased, reaching a maximum at $\mathrm{pH}=5$.

Fig. 4 compares the $\mathrm{pH}$ dependence of the $500 \mathrm{~nm}$ transient absorption bleach signal assigned to the yield of reduced NiP (blue circles) and the $\operatorname{TOF}_{\mathrm{NiP}}\left(\mathrm{H}_{2}\right)$ per catalyst molecule of the system (red squares) determined from bulk photocatalysis experiments reported previously (see ESI $\dagger$ ). ${ }^{17}$ Also shown in Fig. 4 is the ratio of reduced NiP per $\mathbf{R u P}^{-}$(black triangles, calculations detailed in the ESI $\dagger$ ). It is apparent that whilst both the TOF and yield of reduced NiP are strongly $\mathrm{pH}$ dependent, the ratio of reduced $\mathbf{N i P} / \mathbf{R u P}^{-}$is independent of $\mathrm{pH}$. Thus, our results suggest that the yield of reduction of $\mathbf{N i P}$ by $\mathbf{R u P}^{-}$is $\mathbf{p H}$ independent. In contrast, from $\mathrm{pH} 2$ to 4.5 , both the NiP reduction yield and the $\mathrm{TOF}_{\mathrm{NiP}}$ increase. As the efficiency of electron transfer from $\mathbf{R u P}^{-}$to $\mathbf{N i P}$ is $\mathrm{pH}$ independent, the increase in the yield of reduced NiP with higher $\mathrm{pH}$ can be assigned directly to the increased efficiency of $\mathbf{R u P}^{-}$formation due to the $\mathrm{pH}$ dependence of the electron donating function of the ascorbic acid as discussed above. It is also striking from Fig. 4 that at $\mathrm{pH}>4.5$, the $\mathrm{TOF}_{\mathrm{NiP}}$ rapidly decreases despite the yield of reduced NiP remaining high. Such a sharp maximum in the $\mathrm{pH}$ dependence of $\mathrm{TOF}_{\text {catalyst }}$ has also been observed in many other photocatalytic systems. ${ }^{14,15,17,25,39,40}$

As the yield of reduced catalyst is approximately constant between $\mathrm{pH} 4.5$ and 6, the drop on hydrogen generation towards neutral $\mathrm{pH}$ is strongly indicative of a decreasing activity in proton reduction catalysed by NiP. The exact catalytic mechanism for proton reduction using nickel bis(diphosphine) catalysts is still not fully elucidated, with little evidence of the catalytic intermediates in aqueous media. ${ }^{41,42}$ Although protonation of the reduced $\mathrm{Ni}$ species may in principle occur at the pendant amines of the ligand or directly at the Ni metal centre, DFT calculations support protonation of the amines. ${ }^{41}$ This agrees with the dependence of the electrocatalytic activity on acid concentration of bis(diphosphine) nickel

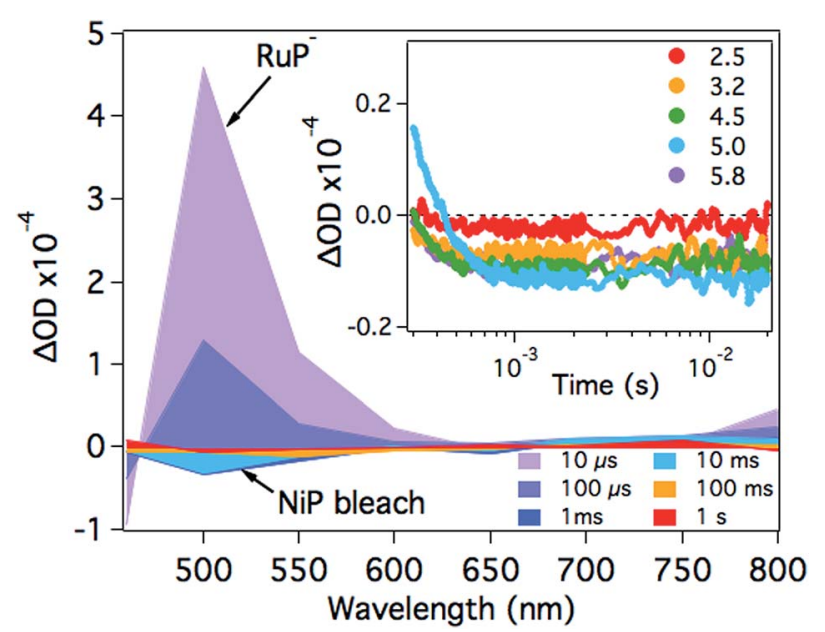

Fig. 3 Transient absorption spectra of a RuP $(4 \mu \mathrm{M})$ and NiP $(8 \mu \mathrm{M})$ mixture in the presence of $\mathrm{AA}(0.1 \mathrm{M})$ at $\mathrm{pH} 4.5$ as a function of time delay. The inset shows the time profile of the negative signal monitored at $\lambda=500 \mathrm{~nm}$, assigned to the loss of ground state absorption of $\mathrm{NiP}$ in the $\mathrm{pH}$ range studied. The samples were excited at $\lambda=355 \mathrm{~nm}$.

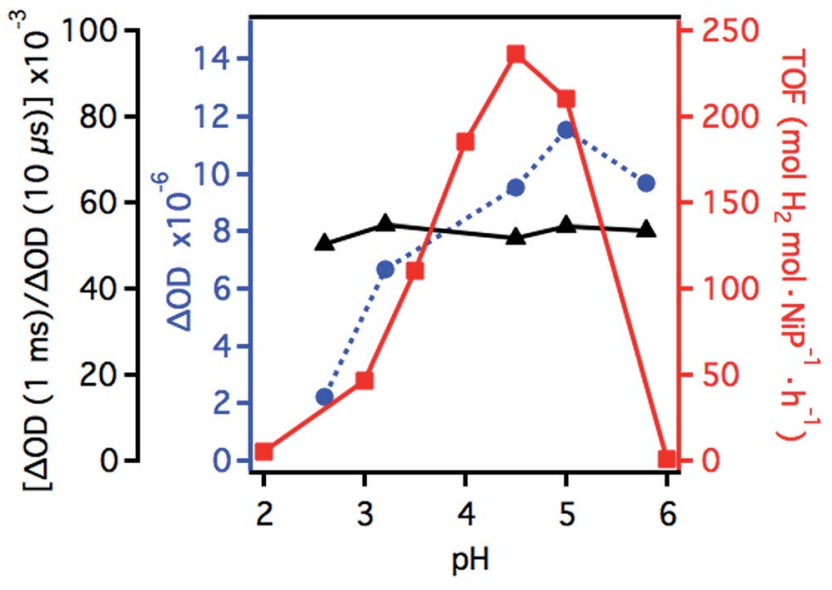

Fig. $4 \operatorname{TOF}_{\mathrm{NiP}}\left(\mathrm{H}_{2}\right)$ of a homogeneous $\mathrm{AA}(0.1 \mathrm{M})$ aqueous solution at different $\mathrm{pH}$ values, containing RuP $(0.3 \mu \mathrm{mol}, 133 \mu \mathrm{M})$ and NiP $(0.1 \mu \mathrm{mol}, 44 \mu \mathrm{M}$; red squares). Transient absorption signal amplitudes of the NiP bleach at $1 \mathrm{~ms}$ (absolute values, blue circles) and transient absorption amplitude ratios of $\mathrm{NiP}$ at $1 \mathrm{~ms}$ and $\mathrm{RuP}^{-}$at $10 \mu \mathrm{s}$ (black triangles).

electrocatalysts, which has been explained by the presence of pendant amines in the second coordination sphere. These amines with a relatively low $\mathrm{p} K_{\mathrm{a}}$ have been suggested to act as proton relays between the solvent and the metal centre. . $^{13,18,19,43}$ Although these studies were mainly performed in pure organic solvents or aqueous-organic solvent mixtures in the presence of strong acids, the electrocatalytic proton reduction activity of NiP was observed to increase towards more acidic $\mathrm{pH}^{17}$ In this article, we detail the dependence of the catalytic activity of NiP on $\mathrm{pH}$ in pure water.

In order to further investigate the drop in the $\mathrm{H}_{2}$ production yield of the photocatalytic system towards neutral $\mathrm{pH}$, the protonation state of $\mathbf{N i P}$ at different $\mathrm{pH}$ values was studied. The titration of NiP with $\mathrm{NaOH}(0.1 \mathrm{M})$ shows two equivalence points, at $\mathrm{pH} \sim 5$ and $\mathrm{pH} \sim 9$ (Fig. 5). In agreement with previous reports, these processes are assigned to the deprotonation of the pendant amines and the second deprotonation of the phosphonic acid groups, respectively. ${ }^{20,44}$ The assignment of the deprotonation of the amines is further confirmed by the presence of only one equivalence point at $\mathrm{pH} \sim 5$ for the titration of an analogous bis(diphosphine) nickel complex where the phopsphonic acid substituents are protected with ethyl ester groups ( $\mathbf{N i P}^{\mathrm{Et}}$ ) (Fig. S4†). A $\mathrm{p} K_{\mathrm{a}} \sim 3$ is calculated from the Henderson-Hasselbach equation for the pendant amines in the ligand with an equivalence point at $\mathrm{pH} \sim 5$ (see ESI $\dagger$ for details), meaning that at $\mathrm{pH}>5$, the amines are largely deprotonated. Since these amines are considered to play an important role as proton relays between the solvent and the nickel metal centre, ${ }^{18,19}$ it is likely that, at less acidic media, the catalytic efficiency is limited by a poor degree of protonation of the pendant amines of the catalyst, which inhibits the ability of NiP to reduce protons to $\mathrm{H}_{2}$. It is worth noting that the photosensitiser employed in our studies contains phosphonic acid substituents. This dye was chosen for consistency and to allow for direct comparison with our previous studies. ${ }^{17}$ The $\mathrm{p} K_{\mathrm{a}}$ 


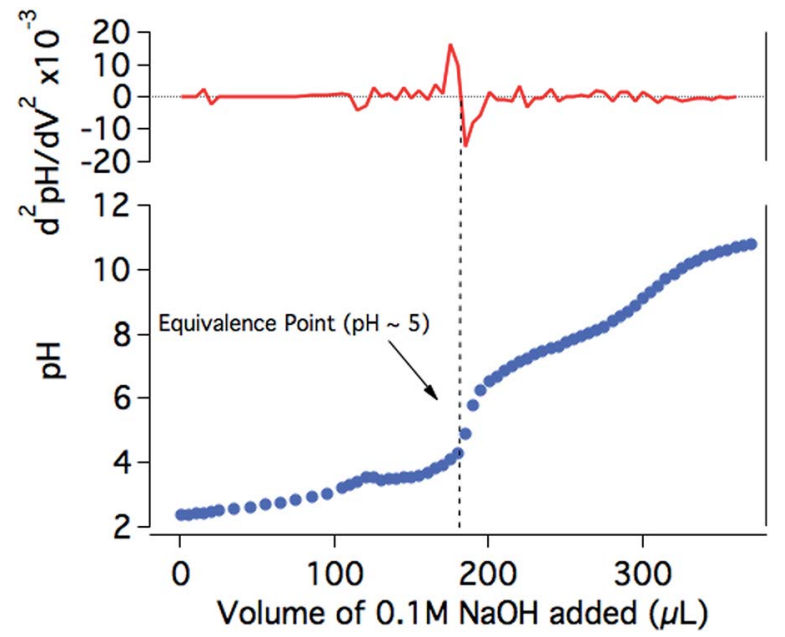

Fig. 5 Titration of $\mathrm{NiP}(0.57 \mathrm{mM})$ in $\mathrm{KCl}(0.1 \mathrm{M})$ with $\mathrm{NaOH}(0.1 \mathrm{M}$; blue trace) and the second derivative of the $\mathrm{pH}$ with respect to the added volume (red trace). $\mathrm{NiP}$ is less soluble below $\mathrm{pH} 3$ and dissolves completely upon the addition of approximately $120 \mu \mathrm{L}$ of $\mathrm{NaOH}$.

values of RuP have been reported to be $\sim 1$ and $\sim 12$, suggesting that the buffer capacity of $\mathbf{R u P}$ within the $\mathrm{pH}$ range employed in this study is limited. ${ }^{\mathbf{4 5 , 4 6}}$

Our results match well with the strong pH-dependencies reported with other proton reduction photocatalytic systems that employ either AA, triethanolamine (TEOA) or ethylenediaminetetraacetic acid (EDTA) as sacrificial electron donors. ${ }^{\mathbf{1 4 1 5}}$ In acidic media, the sacrificial electron donor molecules become protonated, resulting in a poor electrondonating ability due to the anodic shift of the reduction potential. ${ }^{4,17}$ Hence our studies show that the optimum $\mathrm{pH}$ of active homogeneous proton reduction systems is a compromise between electron donating ability of the sacrificial agent and the optimum working environment for the catalyst.

\section{Conclusions}

In summary, we have used transient absorption spectroscopy, combined with titration studies, electrochemistry and bulk photocatalytic experiments, to study the $\mathrm{pH}$-dependence of the electron transfer reactions of a ruthenium-based photosensitiser and a nickel bis(diphosphine) catalyst for the production of $\mathrm{H}_{2}$ under visible light irradiation. Our results suggest that the yield and kinetics of the electron transfer from the sensitiser to the catalyst are independent of the $\mathrm{pH}$. However, at $\mathrm{pH}<4.5$, the catalysis is limited by the number of $\mathbf{R u P}^{-}$molecules available to reduce the catalyst due to the poor reducing character of undissociated $\mathrm{AA}$. In contrast, at less acidic $\mathrm{pH}$, low $\mathrm{TOF}_{\mathrm{NiP}}\left(\mathrm{H}_{2}\right)$ are observed despite the large concentration of $\mathbf{R u P}^{-}$molecules available to reduce NiP. Titration studies of NiP with $\mathrm{NaOH}$ show that at $\mathrm{pH}>5$, the amines are largely deprotonated and electrochemical studies confirm the lower activity at such $\mathrm{pH}$ values. ${ }^{17}$ Since these amines have been reported to play an important role as proton relays between the solvent and the nickel metal centre, it is likely that the catalytic efficiency is limited by the lack of protonated amines in the nickel catalyst. In the wider context, our studies suggest that the $\mathrm{pH}$ of photocatalytic systems using a sacrificial agent has to be adjusted to match the $\mathrm{pH}$ at which the dye is effectively reduced by the sacrificial electron donor and the $\mathrm{pH}$ at which the catalyst can be efficiently protonated. We have also demonstrated how transient absorption spectroscopy, bulk photocatalytic and titration studies and electrochemical experiments can be combined for a rational analysis of limiting factors in a homogeneous photocatalytic system.

\section{Author contributions}

E.P., A.R. and S.S. conducted the spectroscopic experiments. J.R.D. and A.R. designed the experiments. M.A.G. synthesised the compounds and carried out the titration experiments. M.A.G. and E.R. developed the photocatalytic system. E.P., A.R., M.A.G., E.R. and J.R.D. wrote the paper.

\section{Acknowledgements}

Financial support from the ERC (291482, Intersolar to J. D.), the EPSRC (EP/H00338X/2 to E. R., DTG scholarship to E. P.), the European Commission Marie Curie CIG (303650, PhotoCO2 to A. R.), the Christian Doppler Research Association (Austrian Federal Ministry of Science, Research and Economy and National Foundation for Research, Technology and Development), and the OMV Group (to E. R.) is gratefully acknowledged.

\section{Notes and references}

1 B. A. Pinaud, J. D. Benck, L. C. Seitz, A. J. Forman, Z. Chen, T. G. Deutsch, B. D. James, K. N. Baum, G. N. Baum, S. Ardo, H. Wang, E. Miller and T. F. Jaramillo, Energy Environ. Sci., 2013, 6, 1983-2002.

2 P. Du and R. Eisenberg, Energy Environ. Sci., 2012, 5, 60126021.

3 W. T. Eckenhoff and R. Eisenberg, Dalton Trans., 2012, 41, 13004-13021.

4 F. Lakadamyali, A. Reynal, M. Kato, J. R. Durrant and E. Reisner, Chem. - Eur. J., 2012, 18, 15464-15475.

5 A. Krawicz, J. Yang, E. Anzenberg, J. Yano, I. D. Sharp and G. F. Moore, J. Am. Chem. Soc., 2013, 135, 11861-11868.

6 G. F. Moore and I. D. Sharp, J. Phys. Chem. Lett., 2013, 4, 568572.

7 D. L. DuBois, Inorg. Chem., 2014, 53, 3935-3960.

8 H. S. Ahn, T. C. Davenport and T. D. Tilley, Chem. Commun., 2014, 50, 3834-3837.

9 J. R. McKone, S. C. Marinescu, B. S. Brunschwig, J. R. Winkler and H. B. Gray, Chem. Sci., 2014, 5, 865-878.

10 M. Wang, K. Han, S. Zhang and L. Sun, Coord. Chem. Rev., 2015, 287, 1-14.

11 A. Reynal, F. Lakadamyali, M. A. Gross, E. Reisner and J. R. Durrant, Energy Environ. Sci., 2013, 6, 3291-3300.

12 F. Lakadamyali and E. Reisner, Chem. Commun., 2011, 47, 1695-1697. 
13 S. Horvath, L. E. Fernandez, A. M. Appel and S. HammesSchiffer, Inorg. Chem., 2013, 52, 3643-3652.

14 S. Fukuzumi, T. Kobayashi and T. Suenobu, Angew. Chem., Int. Ed., 2011, 50, 728-731.

15 T. Stoll, M. Gennari, I. Serrano, J. Fortage, J. Chauvin, F. Odobel, M. Rebarz, O. Poizat, M. Sliwa, A. Deronzier and M.-N. Collomb, Chem. - Eur. J., 2013, 19, 782-792.

16 A. M. Appel, D. H. Pool, M. O'Hagan, W. J. Shaw, J. Y. Yang, M. Rakowski DuBois, D. L. DuBois and R. M. Bullock, ACS Catal., 2011, 1, 777-785.

17 M. A. Gross, A. Reynal, J. R. Durrant and E. Reisner, J. Am. Chem. Soc., 2014, 136, 356-366.

18 U. J. Kilgore, J. A. S. Roberts, D. H. Pool, A. M. Appel, M. P. Stewart, M. R. DuBois, W. G. Dougherty, W. S. Kassel, R. M. Bullock and D. L. DuBois, J. Am. Chem. Soc., 2011, 133, 5861-5872.

19 M. Rakowski DuBois and D. L. DuBois, C. R. Chim., 2008, 11, 805-817.

20 A. Dutta, S. Lense, J. Hou, M. H. Engelhard, J. A. S. Roberts and W. J. Shaw, J. Am. Chem. Soc., 2013, 135, 18490-18496.

21 P. Du, K. Knowles and R. Eisenberg, J. Am. Chem. Soc., 2008, 130, 12576-12577.

22 A. D. Wilson, R. K. Shoemaker, A. Miedaner, J. T. Muckerman, D. L. DuBois and M. Rakowski DuBois, Proc. Natl. Acad. Sci. U. S. A., 2007, 104, 6951-6956.

23 M. O'Hagan, M.-H. Ho, J. Y. Yang, A. M. Appel, M. Rakowski DuBois, S. Raugei, W. J. Shaw, D. L. DuBois and R. M. Bullock, J. Am. Chem. Soc., 2012, 134, 19409-19424.

24 C. D. Windle, E. Pastor, A. Reynal, A. C. Whitwood, Y. Vaynzof, J. R. Durrant, R. N. Perutz and E. Reisner, Chem. - Eur. J., 2015, 21, 3746-3754.

25 M. Guttentag, A. Rodenberg, R. Kopelent, B. Probst, C. Buchwalder, M. Brandstätter, P. Hamm and R. Alberto, Eur. J. Inorg. Chem., 2012, 59-64.

26 E. Pastor, F. M. Pesci, A. Reynal, A. D. Handoko, M. Guo, X. An, A. J. Cowan, D. R. Klug, J. R. Durrant and J. Tang, Phys. Chem. Chem. Phys., 2014, 16, 5922-5926.

27 B. H. Solis and S. Hammes-Schiffer, Inorg. Chem., 2014, 53, 6427-6443.
28 A. Rodenberg, M. Orazietti, B. Probst, C. Bachmann, R. Alberto, K. K. Baldridge and P. Hamm, Inorg. Chem., 2015, 54, 646-657.

29 D. E. Polyansky, D. Cabelli, J. T. Muckerman, T. Fukushima, K. Tanaka and E. Fujita, Inorg. Chem., 2008, 47, 3958-3968.

30 A. Lewandowska-Andralojc, T. Baine, X. Zhao, J. T. Muckerman, E. Fujita and D. E. Polyansky, Inorg. Chem., 2015, 54, 4310-4321.

31 J. L. Dempsey, J. R. Winkler and H. B. Gray, J. Am. Chem. Soc., 2010, 132, 16774-16776.

32 J. L. Dempsey, J. R. Winkler and H. B. Gray, J. Am. Chem. Soc., 2010, 132, 1060-1065.

33 D. Streich, Y. Astuti, M. Orlandi, L. Schwartz, R. Lomoth, L. Hammarström and S. Ott, Chem. - Eur. J., 2010, 16, 60-63.

34 W. M. Singh, M. Mirmohades, R. T. Jane, T. A. White, L. Hammarström, A. Thapper, R. Lomoth and S. Ott, Chem. Commun., 2013, 49, 8638-8640.

35 C. Creutz and N. Sutin, J. Am. Chem. Soc., 1976, 98, 63846385.

36 D. H. Macartney and N. Sutin, Inorg. Chim. Acta, 1983, 74, 221-228.

37 M. P. McLaughlin, T. M. McCormick, R. Eisenberg and P. L. Holland, Chem. Commun., 2011, 47, 7989-7991.

38 T. W. Birch and L. J. Harris, Biochem. J., 1933, 27, 595-599.

39 Z. Han, F. Qiu, R. Eisenberg, P. L. Holland and T. D. Krauss, Science, 2012, 338, 1321-1324.

40 W. R. McNamara, Z. Han, P. J. Alperin, W. W. Brennessel, P. L. Holland and R. Eisenberg, J. Am. Chem. Soc., 2011, 133, 15368-15371.

41 A. Kochem, F. Neese and M. van Gastel, J. Phys. Chem. C, 2014, 118, 2350-2360.

42 E. B. Hulley, K. D. Welch, A. M. Appel, D. L. DuBois and R. M. Bullock, J. Am. Chem. Soc., 2013, 135, 11736-11739.

43 R. M. Bullock, A. M. Appel and M. L. Helm, Chem. Commun., 2014, 50, 3125-3143.

44 K. Swierczek, A. S. Pandey, J. W. Peters and A. C. Hengge, J. Med. Chem., 2003, 46, 3703-3708.

45 H. Park, E. Bae, J.-J. Lee, J. Park and W. Choi, J. Phys. Chem. B, 2006, 110, 8740-8749.

46 M. Montalti, S. Wadhwa, W. Y. Kim, R. A. Kipp and R. H. Schmehl, Inorg. Chem., 2000, 39, 76-84. 